\title{
Approaches to Organization of Music Bands with Nontraditional Composition
}

\author{
Svetlana Dudenina \\ Russian State Specialized Academy of Arts \\ Moscow, Russia \\ E-mail: dvs_domra@mail.ru
}

\author{
Valery Korablev \\ Russian State Specialized Academy of Arts \\ Moscow, Russia \\ E-mail: dvs_domra@mail.ru
}

\begin{abstract}
The present scientific and methodical research considers the issues of forming and maintaining ensembleorchestral bands for both musicians with disabilities and of any non-standard composition. Given their experience working with differently composed orchestras of the All Russia Blind Association, the authors are approaching culture and art professionals (without reserve) with their innovative, traditional and specific practices. They also offer their knowledge of challenges pertaining to music-making in general. They raise the issues of learning orchestral and ensemble musical material by different student categories, the approaches to the development of creative environment in a team, the repertoire choice and rehearsal practices.
\end{abstract}

Keywords-blind; scientific and methodical research; joint music-making; non-standard orchestra composition; orchestral repertoire policy; related instruments; multiple choice of orchestral parties; creative rehabilitation of disabled people, rehearsal, music teaching methods

\section{MODERN TRENDS OF ORCHESTRAL-ENSEMBLE GROUPS DEVELOPMENT}

The heart of Russian folk orchestra can be described with one word - a fairytale. Even the names of orchestral instruments themselves bring forth a fairytale's coloring: balalaika, gusli, domra, harmonica, bayan, zhaleyka, sopilka, svirel (reed pipe), zabor, rozhok (horn), bich (slapstick), jigsaw, scythe, spoons, rubel' (smoother), whip, ocarina, horns, pennywhistle, nightingale, ratchet, barabanka, kugiklas, pyzhatka, gusachok, rykalka, kopytsa (hoofs). The repertoire usually includes a considerable amount of tales, narrations, fantasies and relating suites, rhapsodies, improvisations, variations, ballades, bylinas and a wide array of processed Russian folklore and ethnos. Fabulousness weaves through the musical ambience of theatrical performances, screening versions of art heritage in cinema and animation. Lastly, this is the great "Russian spirit" of orchestra performers-serious, punctual professionals, open to improvisation and accompanying by ear, to dramatic play and musical joke, satirical songs, to humming and backup dancing.

Despite of certain conservative stereotypes of public opinion, formed largely by so-called "activists for the purity of genre", we delicately but consistently support the traditional composition of Russian public orchestras. Though time moves on, today we see innovation technologies in the area of traditional instruments design and software. Contemporary composers and bandmasters apply new patterns of tones, rhythms and instruments, and, often, this is the result of objective terms a band's concert activity rather than of an experiment. Today there is a demand for a more flexible policy concerning repertoire, performers' groups, performance, rehearsal, advertisement policy, management and other.

In the course of his professional activity, the head of a band has to address a range of issues including the following:

- Availability and professional skills of his performers - the best possible solution is to foster and teach instrumentalists via concertmaster and principals;

- Composing - the best possible solution could be forming of an improvisational sentiment in the group and of a composing drive in the bandmaster;

- State of the enterprise - the best solution is to be directly communicated with the administration;

- Intelligence and interest of art management in the band - the best solution is to understand clearly the necessary influence on art management's artistic taste, its development and education;

- Availability of the necessary facilities-the best solution could be the ability to wait persistently and not let facility managers forget your needs;

- Need for regular and effective rehearsals of any kind - the fastest way to achieve this is to foster necessary assistants among performers and concertmasters;

- Influence of pop music business - the best solution could be the communication and conclusion of contracts with impresario of leading artists, and joint projects development;

- Political influence - the best solution could be to know new political "lines" and try to employ some of them for professional purposes; 
- Availability of patrons of art who are ready to support the folk music development-the fastest way to achieve this is to find and foster the folk art patrons by inviting them to own concerts;

- Public demand for such orchestra-the fastest way to achieve this could be fostering of a decent audience through practical appearances of the orchestra and soloists;

- Musicians' remuneration or the degree of their assessment and gratitude-the best solution is the maintenance of due pay through the earlier set up and funded by philanthropists orchestral fund, trough incentives and due respect;

- Relationship between the performers - the best solution could be the education and development of favorable artistic and psychological environment in the team by personal example and measurement of oneself against the best;

- Other possible objective and subjective factors - the best solution could be found through creativity in problem-solution and business improvisation in tailor-made decisions not contradicting and ruining the already achieved.

A bandmaster often deals with matters far from academia, which at first sight does not seem apparent or quite clear.

For instance, what can hundreds of orchestras do in education, state, district, regional, local and other institutions that practically lack professionals, yet offer preconditions and opportunities to arrange a concert band? Wait for performers from an academy or develop academies on site? What prevents from adding to folk music instruments to symphonic, jazz or pop orchestra groups: the saxophone (Aram Khachaturian's "Sabre Dance"), or the trombone and trumpets (Georgy Sviridov's "Time, Forward!", "Snowstorm"), vibraphone (Sergei Rachmaninoff's suite in A major), the bells (Mikhail Glinka's hymn), the gusli (Vladimir Malyarov's pieces), the clarinet (South Slavic and Jewish motifs), the modern accordion (Eugene Derbenko's pieces), the string double bass, bass and rhythm-guitars, timpani, bells, xylophone, marching bells or horns and such, including the electronic and computer music instruments?

Many attempts to achieve pedal sounding by using horn or bagpipe bourdon failed. Let us recall the performance in orchestra of nakrys (like kettledrums), small horns (nonharmonic folk trumpets), zurnas and zhaleikas (folk clarinet), noting at the same time that they are clear enough and original in the role of occasional solo instruments.

Another example is the castanets and six stringed guitar concurrently played in Spanish-speaking countries like folk instruments and purportedly classic instruments of the symphonic and fold orchestra groups; the Cuban bongos and maracas, Asian bar chimes, modern international flexatone and other - in jazz and pop orchestra groups. It takes many years to find a fine line and only the time and public attention can put an end to this dispute.
It is a great challenge to entirely and fully emulate the academic trend and form an orchestra based just on imperfect design of folk musical instruments for a number of objective reasons. However, it must be understood that without the respect to the origins we are doomed to a deadlock in development of any of the music direction.

\section{NON-STANDARD ORCHESTRAL COMPOSITION NOC}

National and mixed orchestral bands worldwide have long been labeled non-standard. Non-standard bands emerge due to objective and subjective causes. The primary reason stems from the incompleteness of a band and lack of necessary professional staff or physical resources. Therefore, for example, it is difficult to preempt the intake of participants in amateur ensembles. Frequently, there are no funds to afford high quality instruments. At some education institutions, the above is contingent upon the availability of concrete disciplines. While in others, this depends on the level of entrants or their shorthand at certain instrumentation departments.

The subjective causes are even less predictable. They factor in professional, cultural and living standard level of principals, coordinating everything starting from a concertmaster (illustrator) of an orchestral group and director to administration. The problems spread further through administration to related agencies (ministries and offices). Subsequently, according to the "negation of the negation" theory, there are also stage directors, scene directors, radio operators, lighting technicians and so on and so forth.

There are professional orchestra compositions that can be divided into academic and combined. They have been addressed in a fair amount of musical, scientific and methodological literature; they are clearly defined and predictable. The group also includes a number of academic and student groups faithful to the academic composition and repertoire. However, there are also non-standard (and not only folklore) orchestras/ensembles as regards both the musical score and scenic image (further non-standard orchestras, NSO). They have minimal scientific or instructional papers and few available musical texts. Among such bands are child ensembles, student ensembles, amateur ensembles, ensembles of performers with disabilities, and mixed ensembles. All of them are prone to the same sentiments (with petty discrepancies).

Therefore, let us review one of the pilot projects, the orchestra of the All Russia Blind Association (further the VOS orchestra). It belongs to the last category but is illustratory for other band compositions from the standpoint of education (it includes distinguished artists of the Russian Federation, highly educated art professionals, and people unconversant with notation), age (from 7 to 70 years) or institutional grounds (The All Russia Blind Association is a private structure, but attracts great interest of the State, philanthropists and public). 


\section{NON-STANDARD ORCHESTRA'S REPERTOIRE POLICY}

The entire work with NSO is based on the repertoire. Its mastering should be cognitive in its essence and create conditions for the group members' artistic education. It is therefore essential to include in the repertoire works of different times and schools. The orchestra, on one hand, presents a large group of men, each being a personality with own skills, human makeup and problems. On the other hand, this is a single body sharing common ideas, mood and stage performance. The reality is that the team environment and its performance quality entirely depend on the latter.

Repertoire of a folk orchestra should base on folksongs, folktunes and their musical adaptation. Normally, the instrumentalists compose a "mixture" of professionals and amateur performers. Therefore, the preliminary simplified agogics, rhythm, harmonic language and expressive means assist in learning musical pieces. Unlike the professionals who decide all notation problems adequately, the rest performers require special conditions. While picking the right musical piece, one should also factor in that the selection must be learned by heart as the most part of performers are visually impaired or very poor sighted and that this is the only way for them to play their piece.

Compositions and pieces of simple musical form are easier to learn by heart. That is why musical sketches with user-friendly, basically a "square" structure and "simple" sizes, make the core of the entire repertoire. The repertoire of the VOS Moscow orchestra, for instance, has much accompaniment of soloists and instrumentalists. The argument is the orchestra's specific features-blind performers while playing their instruments quite quickly learn to accompany. This is near to their life's rhythm as the cognition of the external world indeed is conducted via intermediaries, via the heard and "seen" by hands.

The visually impaired performers are all the time escorted by guides - at home, outdoors, in transportation. This need in a guide and a leader shows itself in their musical activity as well: a soloist acts as a principal and it is easy to refer to him and make music together. Largely, the bandmaster in the process of his work with soloists, marking out and explaining difficult and poor places in a vocal piece, achieves a more proper performance, intonation and text manipulation through their repetition and comparison. The performers at this time, repeatedly playing and analyzing pieces together with the conductor, get an idea of the correct voice-leading, phrasing, application of the dynamic, acoustic and harmonic effects, and the articulation. Very efficient is the work with professional soloists-instrumentalists. Their talented and mature performance encourages other instrumentalists to understanding not only their part, but the overall design of the author, performer and conductor, raises their expectations of own performance, and enhances musical and general expertise.

The musical range of the VOC orchestra's repertoire by style and genre is almost unlimited: from early music to modern one, from classical, serious music to easy listening and pop music. However, there is no need to run to extremes while planning the repertoire. It is not likely to include in a repertoire of the orchestra with disabled performers pieces of music that are difficult for them to grasp (e.g. oriental music, pure jazz, or pieces of ultra-modern composition trends such as aleatory music, sonorism, dodecaphony and such). Though this is achievable, the work with such music is time consuming and challenging, and the expected effect and stylistic matching is very difficult to accomplish.

The necessity of rearrangement for instruments is something special for any non-standard orchestra and for the VOS orchestra particularly. Its list of played and still going music pieces includes Vasily Andreev, Joseph Tamarin, Vladimir Malyarov, Dmitry Borodayev, Viktor Gridin, Eugene Martynov, Eugene Derbenko, Alexander Tsygankov, Georgy Sviridov, V. Wilenius, Kirill Molchanov, Matti Rantanen, Vladimir Korablev, Sergei Dudenin, Alexander Dmitriyev, Alexander Borodin, Nikolai Rimsky-Korsakov, Mikhail Glinka, Sergei Rachmaninoff, Enrico Cannio, Franz Schubert, Edward Grig, Maksim Dunayevsky, Alexander Tsfasman, Blanter, Arkady Ostrovsky, Edward Kolmanovsky, Jan Frenkel, Grigory Ponomarenko, Nikolai Lysenko, Aram Khachaturian, Petr Bulakhov, Alexander Varlamov, Alexander Gurilev and other composers, concert pieces, fantasies, adaptations of folksongs and melodies, popular pop music. The majority of them have already been instrumented for different orchestra compositions, and almost all of them required creative adaptation and serious alteration of the parties with respect to the performers' individual differences, their psychological and physical nature-weakness, illnesses, scenic excitements, need in the partnership, collaboration and individual artistic selfexpression.

The alterations consist of repetitions, recapitulations, simplification or texture development, streamlined logic structure of the form, rhythm, harmony, dynamics, agogics, phrasing and intonation, and, if possible, duplicated major orchestral functions. Basing on the learned material, played and perfected in the course of performances, bandmasters continue perfecting and renewal. This translates to the selection of pieces of music according to picked genre, artistic image, the performers' interests and concert perspectives of the ensemble; to the development and mastering of parties; transposing, soloists' rotation; change in the orchestra instrumentation, and, finally, artistic experiments. Based on the experience, it can be said that the NSO's repertoire is revised $30 \%$ to $70 \%$ annually.

\section{INDIVIDUAL AND GROUP CLASSES}

The orchestra members are far from being alike in their natural skills, level of culture and musical training, and this forms the principal difficulty in work with an amateur ensemble. The bandmaster often has to learn the beginner afresh, taking into consideration his age, musical skills, commitment and readiness. Critical is to find for the new member his place in orchestra whereat he would put his talents into practice to the maximum. ${ }^{1}$

${ }^{1}$ Mikhail T. has the first group of disablement. He joined the orchestra in 1995, had no musical background, but learned on his own to play the accordion, selecting melodies by ear. The main challenge of work with him 
Thorough individual work here means the world-it should not be too challenging and at the first opportunity should be fulfilled in an orchestral playing so that the beginner could see results of his efforts as soon as possible. That is why in an amateur orchestra a method of parties' variation is frequently used, when instrumentalists, considering their competence level, are given orchestral voices of various complexity. In time of grown possibilities, parties get more complex and are taken to the level of original concept. ${ }^{2}$ This process may take years, can stall at certain points or exceed by complexity the designed version in some cases. The technique is used in two instances. The first one is designed for putting an instrumentalist on the orchestra as soon as possible, the second is for the gradual development of his skill. There are times when an orchestra is joined by a performer with sufficiently high musical potential, able to play a party of higher complexity than designed. Then comes an opportunity either to write a more challenging orchestral voice or give such performer a chance to improvise within the form and plan. Otherwise, this is about a performer who knows the repertoire, his orchestral voice or its certain variation and can learn in a more complex way. The method described above is an effort to develop the orchestra members that are training and perfect their musical and technical skill on the principle of simple-to-complex. It is noteworthy that the original score is notated traditionally - if, by using this technique, note down all voice versions, the complete music score reaches in quantity of lines the quantity of real and potential participants.

There is a term in the performers' practice called "the school of imitation" meaning a trainee's intention to copy his trainer, colleague, partner musician, and the approach of conveying the system of music ideas and playing techniques. The merger of a trainer's experience with trainee's own creative findings gives rise to a new original musical talent. Our work with the blind performers applies the technique of

is that he hardly remembers anything by heart and is almost blind. His attempts to play the balalaika second and double bass were a failure. However, this seemed quite strange to the bandmaster as Mikhail played the accordion, sufficiently purely voices and was able to pick fancy melodies by ear. It turned out that he reproduce by ear only the earlier heard pieces or songs. It was decided to teach him to play the tenor reedpipe and to include him in the orchestra's reedpipe section. The results exceeded all expectations. According to the decision, he joined the core orchestra on the large drum, which, as time showed, was the right decision as well. Mikhail received the references - the bass and melody. He is not dependent on pitch difficulties and concentrates on the rhythm, which he naturally possesses. His active participation in rehearsals and performance activities of the orchestra produced good results.

${ }^{2}$ Galina $P$., for instance, does not have any vision deficiency. Plays in the orchestra for four years. Her training method applies the parties' multivariance. She is the musician with no musical background but with a great desire to play in the orchestra and to master the instrument. Because she tried to learn the accordion at home, it was decided to begin teaching her this particular instrument. Her first parties evolved from single pedal notes to added second and third voices, more difficult rhythm and melodic phrases. Later the performer began to play polyphonic chords, difficult rhythmical figurations and solo. To keep up her interest she was offered to learn also the keyboard gusli, and her parties today are written for both the accordion and the gusli. Moreover, Galina has learned to play the reedpipe alto, and is of a large help to her blind fellow performers in their getting about, changing their concert uniforms, escorting to rehearsals and such. learning "from fingers", from recorded take and rehearsal work in groups (partner-orientated).

From old times, the folk music traditions have been passed by word, and even when musical texts appeared, the folk musicians did not have opportunities to learn them and continued to use the old and time proved method. This longstanding approach has been used to present and remains the basic tool for the blind performers. The blind's hearing becomes more active, the performer is permanently tuned outward, which helps him remember and later reproduce what he has heard. A bandmaste working with an instrumentalist one-to-one, plays to him the whole piece and then breaks it down into logically complete segments, motifs and phrases. While playing them he makes the trainee repeat these segments, corrects the fingering, articulation techniques and text errors. Further, the participants put together all the parts into one piece and try to produce it. Learning a party by heart requires at least two rehearsals to learn, repeat and fix the mastered material (everything though depends on the musical memory and skill of the trainee).

Today many performers (even not blind) vote for the method of learning a party from recording. A bandmaster records a sound party and a performer tries to learn his orchestral voice on his own, auditing and reproducing as many times as it is needed. Let us underline that the parties are recorded together with the main theme so that a performer can play the instrument following the head-motif, which later helps become integrated into orchestral tissue.

Learning notes in Braille is the NSO orchestra's another basic rehearsal method ${ }^{3}$.

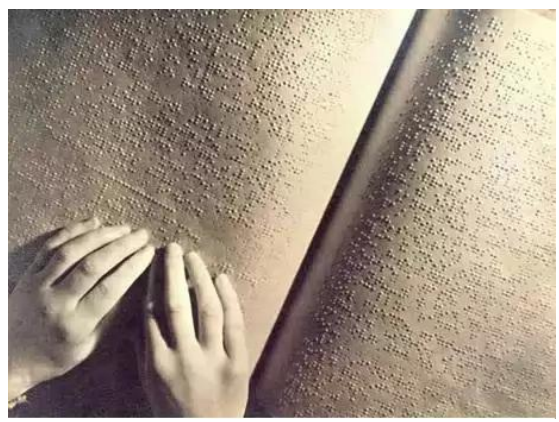

Fig. 1. The example of the Braille recording of notes

Knowledge by instrumentalists of the Braille recording system significantly facilitates the bandmaster's work and helps the performer immensely. Learning of the repertoire by the blind performers requires remembering and keeping in mind a large amount of orchestral parties, which, with some minor exceptions, is hard if not impossible. With the Braille, the blind musician is able on his own to learn, repeat, remember his orchestral voice, assist the bandmaster in

\footnotetext{
3 The tactile writing system, invented by blind Frenchman Louis Braille (1809-1852), first appeared in Russia in 1881. The first Braille books were printed abroad in 1881-1898, primarily in Germany, by the Schulz printshop. Their printing pioneer in Russia became the well-known public person Anna A. Adler (1861-1924).
} 
writing parties for himself and other ensemble members, and even give a hand to performers not acquainted with the system ${ }^{4}$.

Many instrumentalists in the VOS orchestra have residual vision. Reading of common music text on a standard music paper is unobtainable to such people ${ }^{5}$, so the VOS has developed and widely applied the notes recording on an enlarged musical staff wherein the size of a music text has been enlarged several times against the customaries ${ }^{6}$. Reading the text does not require learning by heart. However, such noting is time-consuming and requires certain expertise and technical aids (corresponding paper with music staff, thick markers and different color markers, etc.).

Modern musical edit programs reduce this complexity:

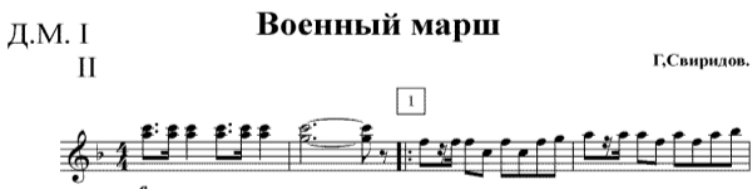

Fig. 2. Scale $100 \%$

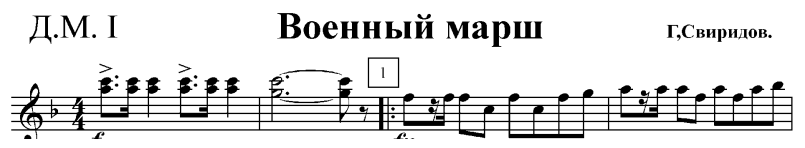

Fig. 3. Scale $120 \%$

${ }^{4}$ Vladimir B. has been blind from birth. Attended musical school specializing in piano. Learned individually to play seven more instruments, which, along with his perfect pitch, allows him substituting other performers in situations of urgency. At one of the performances, he managed to play without the preliminary rehearsal the entire piece of the keyboard gusli, thus helping the bandmaster resolve the force major. Being a skilled performer, he is quick to help another performers learn playing their instruments, study the Braille, learn new parts and so on and so forth. For several years he has been the principal of the bayan section and is one of its members today.

${ }^{5}$ Maxim $P$. has the first group of disablement and reading of the musical text is impossible for him. For him there are specially enlarged font parties on enlarged staff, written with the use of different colored markers and watercolor pens for the purpose of his better orientation in the musical text. Graduate of the State Specialized Arts Institute in 1997, specializing in the bayan. However, on the bandmaster's advice he has decided to master the domra alto and became the principal of this section. In the course of the years spent in the orchestra, his mastery of the playing techniques has made the speech more bright and beautiful and the tremolo depth more mellow. Besides the domra alto, he also plays the balalaika primo and bass reedpipe. It has a good musical memory and knows the bulk of the parties by heart. On the conductor's instruction, he can develop his orchestral voice, play by ear and improvise.

${ }^{6}$ Vladimir $G$. has the second group of disablement, and thus can play only the large font musical text. Has the special post-secondary education (vocal). Has been with the orchestra for over 10 years. Vladimir possesses good artistic ability, does not stop on the achieved and continues to master new repertoire and images. Has taken up complementary drums and gusli on the bandmaster's recommendation. He actively assists the young performers in the professional, social, and cultural adaptation.

\section{Д.М. I Военный марш г,свиридов.}

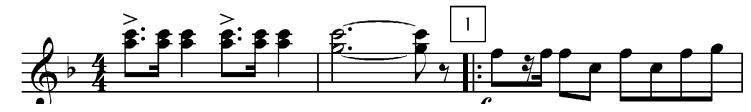

Fig. 4. Scale $150 \%$

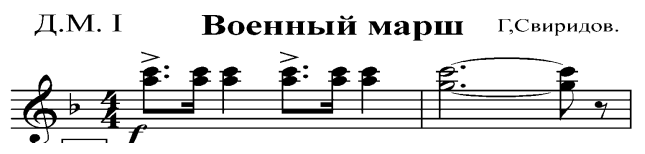

Fig. 5. Scale $220 \%$

As a party starts to sound more steadily during one-toone classes, it becomes possible to bring together two or more performers and get on to group classes. In the course of rehearsals the bandmaster should not attempt to merge the entire composition; it will be enough to join just one of its parts. The rehearsed piece can be recorded on tape-recorder and jointly listened to- this helps the players track their errors as if sideways, and, at the same time, makes a rehearsal more creative. Concurrently, the repeatable playing and hearing helps consolidate the material.

All reviewed techniques should aimed at both the development of a need for self-improvement of one's own knowledge, skills and technical exercise, and of general musical education. The latter is unachievable without regular home exercises that lead to concrete learning results and develop the artistic character of the performer.

The problems of general education, fostering and development of orchestral musicians are enormously important. In this context, some more techniques aimed at the development of the above merits should be mentioned.

\section{AuXILIARY TERMS OF THE ENSEMBLE'S STABILITY.}

Firstly, it is the learning to play by the performers of the second instruments. Unlike the professional band, the amateur one is driven by sheer enthusiasm, love of music, need for self-expression and communication with people of similar views and interests. But life and problems interfere with one's aspirations and with an orchestra with the disabled musicians such asperities appear more often. Illness, discomfort, the need for a guide, a family or work circumstances, change in residence and much more - all these cases may lead to a temporary or permanent withdrawal of some of ensemble members. Specifically, a need arises for learning some second instruments, which does not contradict the process of education, and, vice versa, diversifies the performers' orchestral practice. Sometimes, the performers themselves initiate their learning of parallel instruments, and the bandmaster, depending on the policy and members' possibilities, either encourages or rejects such initiative. It happens that the bandmaster resorts to this maneuver to fascinate, incite or organize the performer.

A matter of choice of the second instrument largely depends on its commonality with the prime instrument. For instance, it is easy after the balalaika alto to take primo, after domra alto to play domra bass, and the keyboard gusli after 
accordion, the domra after the guitar and so on. Nevertheless, illogical shifts can sometimes happen. For instance, from the bayan to the domra, the drums, the balalaika or the gusli; from the wind instruments to the traps; from the strings to the wind and so on. A party played on the parallel instrument should be easier in the terms of its musical and technical performance. An orchestra where a performer can play different instruments becomes more sustainable in terms of its concert activity, more mobile for tours, is appealing to audience (sometimes, on the director's idea the instruments are changed right on stage), and more team-oriented. Again, mastering of second instruments and the possibility of replacing one instrumentalist with another is considered to be one of the kinds of the teamwork.

Secondly, the presence in the orchestra of a certain number of people with vision or residual vision is a must. As explained earlier, the blind members need a guide, a leader, to be able to contribute to the joint music making. That is why it is likely that each orchestra section (primarily, the acoustic bass, bass and the traps) has a performer who can see the conductor, the music text and be a guide to other performers. There is a great need in such people in the orchestra as this resolves the problems for the blind and partially sighted musicians with the playing, pausing, slowing down, acceleration and stops in compositions, as well as with unforeseen circumstances that may arise at concerts. The assistance of the people with vision is also needful as everyday problems occur: uniform change, instruments handling or escorting home, onto the stage or during excursions through halls and such. The blind may also be of help to his fellows where possible-including the process of learning, repetition of a party, reading in Braille, its study, spatial orientation and so forth ${ }^{7}$. The VOS orchestra includes, as a rule, no more than $50 \%$ of the blind and no less than $20 \%$ of the people with vision or partially sighted who can be guided by the conductor and enlarged musical texts.

\section{CONCERT APPEARANCES}

Rehearsal classes alone usually aren't the inception to inspire the performer's love for the ensemble playing. In this respect, concert appearances help the musicians feel the fruit of their painstaking work to the full extent. The preparation for concerts is of a particular importance for amateur ensembles - it makes the core of their orchestra's existence, brings the orchestra members together, inspires its further growth, enforces the performers' moral quality and stamina, and largely determines their psychological state. Conclusions drawn from the evaluation and comparison of

\footnotetext{
${ }^{7}$ Sergey S. has lost his sight in the result of an accident when he was 18 years old. In 1994, he came to the orchestra, played few guitar pieced, learned "by fingers". He has fine hearing, memory and timekeeping. Initially he planned to play just guitar, but after an interview with the bandmaster decided to play also the balalaika primo, which brought splendid results. After being quickly acquainted with the instrument, he has learned the necessary orchestral repertoire from memory, not knowing the notes. Being a quick learner, he needs the minimum of time to learn a new party, perfectly handles the musical text and can pick accompaniment by ear. Sergey gladly shares his experience with the beginners.
}

conducted concerts are prompting and encouraging further rehearsals and new creative efforts.

An artist's conduct on stage has become more unchained in the past 25-20 years. Meanwhile, the blind performer's line has not changed and a tremendous effort is needed to make him more footloose on stage so not to attract the public's attention by statics, unnatural or unfitting moves. While preparing for a concert and devising the art direction, the bandmaster should foresee audience's response and focus on details that would pass the listeners' attention off the VOS orchestra's specificity. This could be a soloist that concentrates the viewer's interest on him or one of the performers who can stand up in the middle of play with his solo passage, smile and make the proper, proven gesture, blind or not, or a communication in the play of the sighted instrumentalists with the blind as equal, etc. Generally, such challenges have always been present in the VOS ensembles and will remain, but in terms of a concrete group, this aspect may be polished by regular work with the blind musicians, making their scenic conduct more natural.

Concert appearances present not just the appraisal of achievements, but an essential training philosophy as well. Sometimes one public performance equals to weeks and months of hard individual and collective rehearsal job. Taking into account this peculiarity of concerts, the bandmaster should very thoroughly think over the goals, plan and repertoire of the performance, properly arrange the backstage and stage work with the maximal efficiency of all participants.

The opportunity to become a part of an ensemble provides a wide range of the blind and partially sighted people with a supportive environment for their art education and spiritual development. Though orchestras do not present academic institutions as such, the teaching, learning and creative activities there, as the criterion of the orchestras' livability, are vital for their artistic development.

Personal experience of an orchestra member integrates into the skill of the rest, and as a result, emerges a new synergetic level of quality - the collective wisdom. The bandmaster's techniques here are very diverse-starting from a simple interview one-on-one or in a small group to a joint visit of theaters, museums, concerts, churches and other public institutions that spiritually and morally enriched all the participants. This becomes increasingly important the personal skills of a coach, his interpersonal skills, decency, knowledge of the trainees' psychology, their everyday problems and interests, his managerial abilities, his gift of listening and help, ambition, love of music in general and of folk musical instruments in particular and more. These huge strata where one can be creative, experimental and scientific, and what is more important; this is an opportunity of spiritual development of all the parties.

Finally, the biggest and the most demanding challenge of the bandmaster's efforts is to bring together all orchestra voices and to lead the orchestra through the performance. The matter of proper joint music making has been topical in any ensemble from a duet to a combined orchestra. These challenges and peculiarities for the VOS orchestra, however, 
are incomparably bigger. The conductor's work in such ensemble should be carefully considered and arranged. He has to employ all available means: high education, culture, proficiency, intuition, analysis, physiological and psychological knowledge, general expertise, heart-blood, managerial qualities and authority and such. Also these include special forms of conducting the orchestra- the word, manual technique, beat aloud, singing, direction with the assistance of a musical instrument or any other special technique of sound regulation, and an active employment of soloists, preparation and teaching of the section principals, explanation to sighted musicians of their vital role in the transfer of information through them from the conductor to the blind performers.

Besides the manual and sonic (claps, voice, sound) means it is desirable to employ the specific technical devices, for example, metronome, synthesizer, instrument of ultrasonic beat and their analogs. It is necessary to concentrate the performers' attention on places of tempo and dynamic alterations, namely on the beginning and end of the piece, on slowing down or acceleration, holds, stops, crescendo, diminuendo, sf, sp, accents, culminations, etc. This work begins in the individual and later is continued in group classes, but in the course of general rehearses the permanent control over the earlier achievements is required.

An inconsistent participation in rehearsals and potential stage problems (agitation, a forgotten party, sudden disconnection of the microphone, etc.) impel the bandmaster to develop some performers' readiness to improvise at any point (of course within the form and taking into account the conductor's conception) - to support the "suppressed" orchestral voice, support the accompanying or rhythmical function in the orchestral tissue, to duplicate or evolve, to enrich the structure or harmony. Such improvisatory development of the material, unusual for professional bands, is being accumulated in the course of mastering the compositions, as on the conductor's request, one or other performer takes up the party of another player who is absent or temporary off. Some expert performers develop in the course of time the skill of improvisation without the outward prompt. Due to these efforts, the concert performance is achieved with the smallest loss, with the inspiration and the performers' greatest yield. It is also distinguished by the original sounding of the orchestral literature.

The NSO's specific nature (attention to its members, difficulties with mastering the parties, the need for a certain number of leads for the blind performers during joint music making) creates many challenges, solution of which is above one man's strength. It can be ascertained that at least three professional principals are needed for normal activity of an orchestra of 20-25 performers. It is also possible when they all take part in the performance, and the conductor takes the role of the principal accordion, percussion, contra bass and other. (That is how it is in the VOS orchestra). In the case of the manual guidance, the conductor should focus attention on his gesture, making its more pronounced, accurate and wide, even if this does not look aesthetically pleasing from the side.
In the setting of different concert halls the balance of orchestral tone is likely to change; therefore, the bandmaster should hold an acoustic rehearsal before the performance and adjust the group's tone. As a rule, this is done with the assistance of a sound director sitting out front. Such rehearsal is also valuable to the performers, since it helps them adjust to their instruments' special tone, and the group and the orchestra in general are getting used to the concert setting. It is essential to give forth in advance the concert program, so that the search for notes by the performers during the concert does not set off the program-prescribed rhythm.

Master tuning in an amateur orchestra is quite a lengthy process, so it is essential to allot the time for this in advance. The pre-concert preparations is frequently time-limited, full of unexpected circumstances, and are very busy. The bandmaster should double his attention to his tone, the accuracy of remarks and the mood. It is necessary to establish a concentrated constructive atmosphere and distract the performers from their emotional stress over purely technical difficulties, and to inspire them. This should be kept in mind during the performance and even after. No flat remarks should be made on the performance day on no account, since the already nervousness of the disabled participants can aggravate to the maximum. It is best to do such things during the following after the concert rehearsal in a restrained and civil manner, with reference to similar examples from the practice of the professional ensembles and musicians, possibly, even in the form of a joke or a hint.

\section{EXPERIMENTS IN PROMOTION OF THE NSO MEMBERS' LEARNING}

1. Whilst with the VOS orchestra a number of pilot schemes have been tested. One of them presented the learning by the performers to play second instruments in the core folk orchestra. The bandmaster himself or the principals of the sections taught the performers individually, in groups and at general rehearsals, using the principal time rather than the aftertime. Say, the bandmaster invites to the domra group rehearsal the accordionist who picked domra his secondary instrument, to learn it through explanations, audition and his partners' advice. Then comes the moment, when at the general rehearsal the bandmaster offers him to play the second instrument. Later such acquirement may be used in critical situations during performances. This increases the performer's mobility, his commitment and knowledge of the party, and secures his musical skills, fostering further creative development.

2. Involvement of the most of the folklore section performers in the reed pipe orchestra. We put the idea into life and, judging by the reaction of the audience, it could be reckoned as successful.

Under the experiment, the performers have been offered to take on one of the reed pipes beside their principal instrument. Further joint music making was the goal. Those performers who got interested in the project took catch-up classes, not related to the work of the regular strings group. Over time, after reviewing the results, we saw that the performers that took the reed pipes, became more active in 
the orchestra's work-started to more regularly attend classes, increased interest in the classes and performances, improved the quality of material they learned; increased their responsibility, streamlined the relationship and mutual assistance. Their musical sense, artistry, self-confidence and adequate self-esteem have increases as well. This group formed the backbone of the orchestra.

3. The use of the parties' multi-variance. The result of this experiment speaks for itself. Such practice allows involving the instrumentalist in the teamwork almost from the primary rehearsals and bringing the participant's capacity to high proficiency.

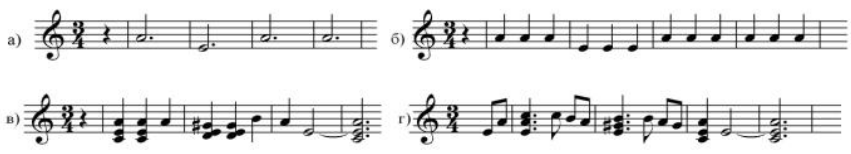

Fig. 6. The accordion party.

a)

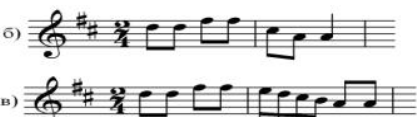

Fig. 7. The domra piccolo party.
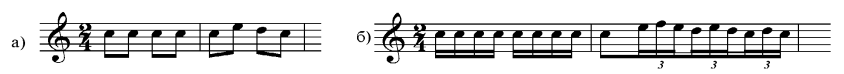

Fig. 8. The reed pipe party.
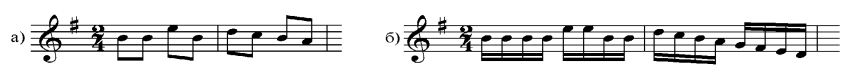

Fig. 9. The bayan party.

Corresponding trainees are making progress much faster than the performers who train under the traditional education model. They are quicker in their perception and response to the conductor's feedback, are better oriented in musical literature, able to hear other parties. They understand and learn to utilize the improvisation technique. Moreover, this group is psychologically ready for modification of the environment, which is especially important onstage.

\section{CONCLUSION}

As can be seen above, the work of the non-standard orchestra leaders, alongside pedagogical, artistic and educational problems, is associated with an abundance of unconventional difficulties. The authors hope that their thoughts set forth above will find understanding of those who take keen interest in the development and function of the orchestral-ensemble bands with nonstandard composition.

\section{REFERENCES}

[1] Chunin V., Contemporary Russian Folk Orchestra. - M., 1981, 1990.

[2] Imhanickij M., At the root of the orchestra of Russian folk culture. M., 1987.
[3] Kogan G., At the gates of Excellence. - M, 1969.

[4] Peresada A., Orchestras and ensembles of Russian folk instruments. M., 2004.

[5] Shakhmatov N., Instrumentation for the orchestra of Russian folk instruments. - M., 1985.

[6] Piston W., Orchestration. - M., 1990. 